\title{
SOME EFFECTS OF CARBON IN THE PRODUCTION OF SINGLE CRYSTAL SUPERALLOY CASTINGS
}

\author{
John R. Mihalisin ${ }^{1}$, John Corrigan ${ }^{2}$, Michael Launsbach $^{2}$, Eric Leonard ${ }^{1}$, Robert Baker ${ }^{3}$, Brian Griffin ${ }^{4}$ \\ ${ }^{1}$ Howmet Dover Alloy, Dover, NJ \\ ${ }^{2}$ Howmet Corporate Engineering, Hampton, VA \\ ${ }^{3}$ Howmet Hampton Casting, Hampton, VA \\ ${ }^{4}$ Howmet Research Corporation, Whitehall, MI
}

Keywords: Investment Casting, Single Crystal, Scale, IGT, CMSX-4 ${ }^{\circledR}$, PWA1480, PWA1484, Carbon

\begin{abstract}
$\underline{\text { Abstract }}$
Among the numerous challenges of producing single crystal superalloy castings, with intricate cooling passages and increased size, is that of minimizing scrap and rework. The use of advanced single crystal alloys in today's industrial gas turbine engine castings has exacerbated two of the primary causes of rework with these castings, metallic-oxide inclusions and surface scale. Increasing the carbon levels in these alloys is known to reduce the levels of these defects. These alloys typically contain levels of carbon that are considered to be very low, at less than 100 ppm. Studies have shown that increases of the carbon level on common single crystal alloys, such as PWA 1480, PWA 1484 , and CMSX $-4^{\circledR}$ can significantly reduce processing time and cost during casting production.
\end{abstract}

\section{Background}

Clean, defect free superalloy castings have been the objective of the gas turbine industry since its inception. It has been well known, that non-metallic inclusions are often the initiation sight for failures. In the quest for higher operating temperatures and stresses for these castings, the design of today's turbine blades has become more complex with thinner cross-sections and intricate cooling passages. As a result, non-metallic inclusions that were once relatively innocuous are now a limiting factor in turbine airfoil design.

Over the years, technological progress has led to the development of uni-directional casting techniques to produce single crystal castings with improved mechanical properties, as shown in Figure 1. These alloys contain no grain boundaries that limit the high temperature strength of conventional polycrystal alloys. In addition, the anisotropic properties of single crystals were taken advantage of by controlling their orientation in the production of castings. Early alloy designers considered carbon to be primarily a grain boundary strengthening

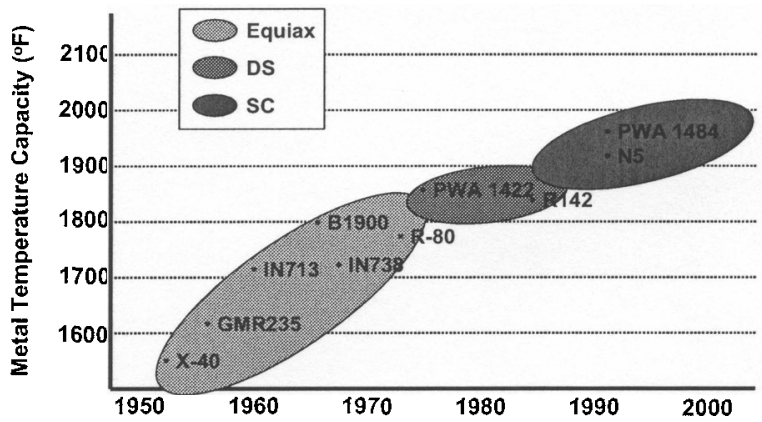

Figure 1: Superalloy Temperature Capacity

element, along with other elements such as boron, zirconium and silicon, commonly found in polycrystalline superalloys. Their conclusion was to reduce the amount of carbon in single crystal alloys as much as possible. They were aware of the fact that carbon played an important role in vacuum melting by reducing the oxygen concentration in the melt, which required some carbon to be present in the alloy.

The role of carbon in reducing oxygen is accomplished by what is commonly referred to as a "carbon boil". Without this step, oxygen levels may approach $100 \mathrm{ppm}$. Carbon reacts with oxygen to form carbon monoxide, which is readily removed at the low pressures obtained in vacuum melting. ${ }^{1}$ This drives the reaction to virtual completion, resulting in effective removal of oxygen. Of course, there must be sufficient carbon present to balance the amount of oxygen present. It was believed; however, that there would be sufficient carbon in the raw material for this purpose. At the time there was, and is at present, a concerted effort to use high quality raw materials with low levels of oxygen. 
Limiting carbon to low levels had another effect, which was to reduce or eliminate carbides in these alloys. Carbides appear in alloys with the presence of strong carbide forming elements, when the concentration of carbon becomes larger than $50-100 \mathrm{ppm}$. Carbides were thought to be a failure initiation site, and the reduced amount of carbides was thought to be beneficial. Thus, early single crystal alloys were generally specified to be less than $50 \mathrm{ppm}$. carbon.

\section{Early Production Experience With Single Crystal Alloy Castings}

It was observed during vacuum melting of PWA1480, while producing castings that a film formed on the surface of the melt. The presence of this film made accurate temperature measurement by radiation pyrometry difficult.

Another early observation was that PWA1480 castings had a tendency to form very narrow secondary grains, which grew parallel to the direction of solidification. These grains were typically 0.02 " to 0.125 " in width and 0.250 " to 2 " in length before being overtaken by the more favorably oriented principle grains. The secondary grains are commonly referred to as sliver grains, and in many instances have been found to originate at oxide inclusions.

It was also noted that PWA1480 castings tended to form a scale on certain surfaces, notably those furthest from the chill on cope surfaces. Its outward appearance was that of a rough, dark oxidized layer, as shown in Figure 2.

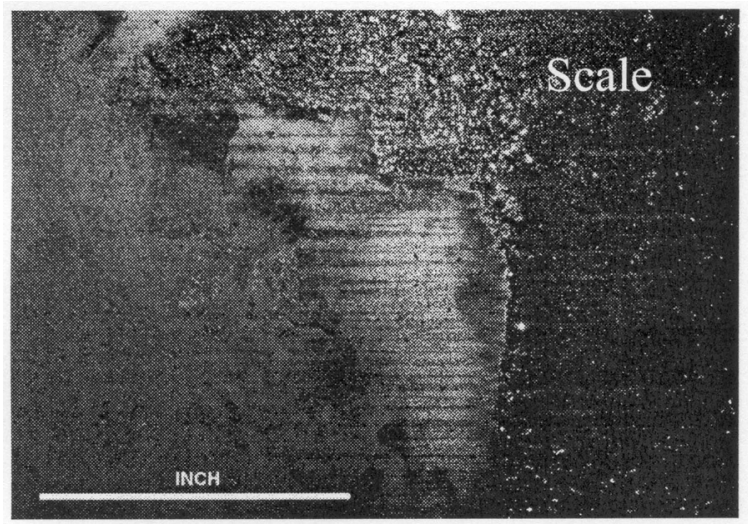

Figure 2: Surface scale (dark area on the right) on a CMSX $-4^{(3)}$ casting

Metallurgical studies revealed the layer was superficially oxidized and the body of the scale was a layer of metal enriched in elements, such as tantalum and titanium. The composition and presence of various phases in the scale differs among the alloys. For instance, the scale is primarily Ta-rich in PWA1480, while it contains a number of phases in CMSX $-4^{(2)}$. Figures 3 and 4 show the typical CMSX $-4^{(3)}$ scale.

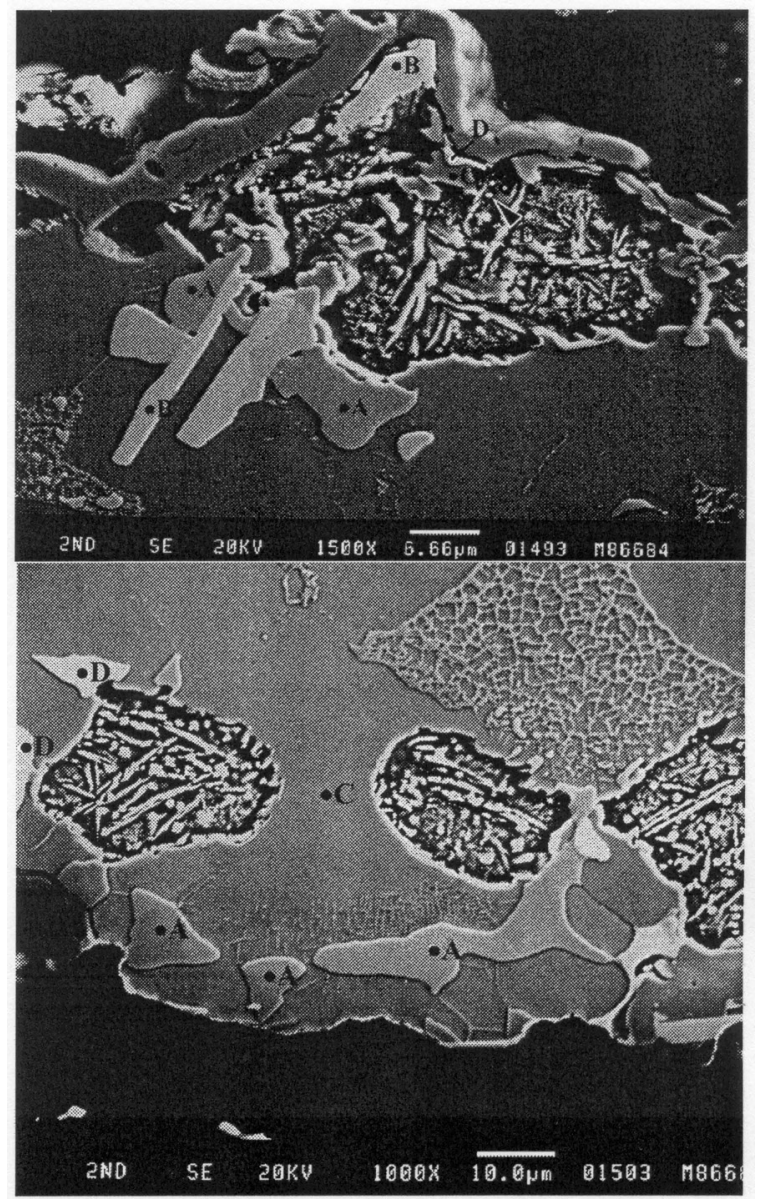

Figure 3: Higher magnification views of CMSX $-4{ }^{\circledR}$ scale. EDS spectra of phases above are shown in Figure 5. B, DSigma $(\sigma)$, A, E - Unidentified Cr-rich, C - eutectic $\gamma / \gamma^{\prime}$

Although this scale does not typically impact casting quality, its removal leads to the undesirable consequences of additional labor and dimensional variation, as it can only be removed by mechanical means. This increases production cost and time. 


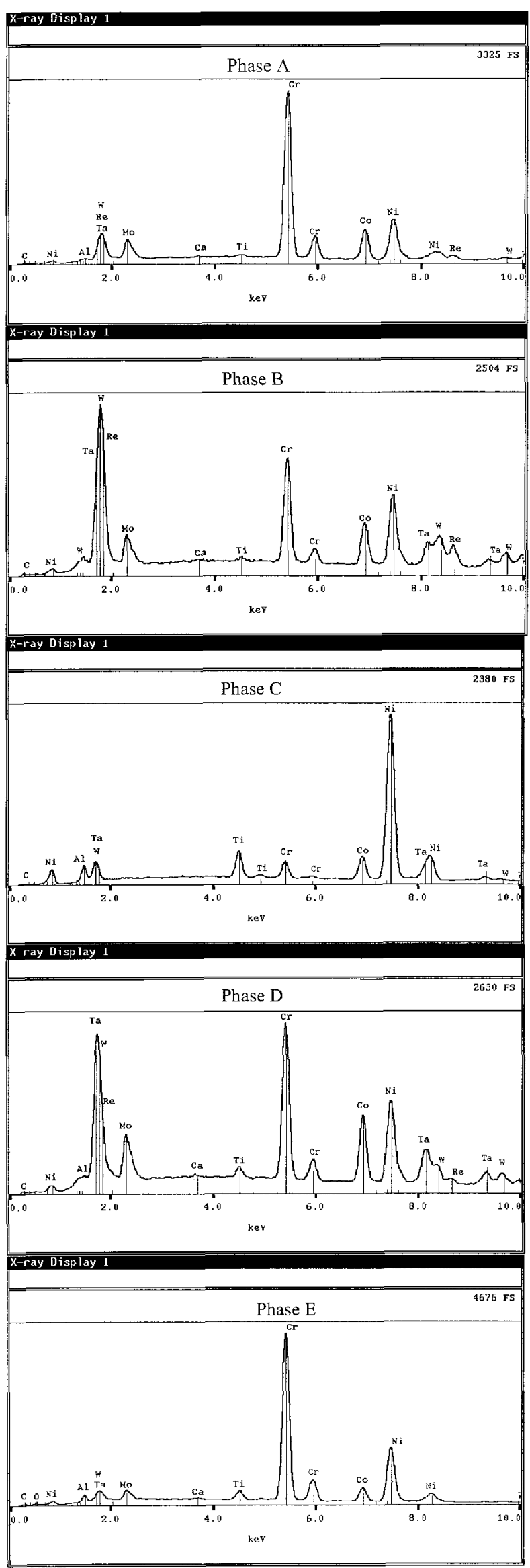

Figure 4: EDS of CMSX-4 ${ }^{(\mathbb{B}}$ shown in Figure 4
It was believed, at this time, that some of the sliver grain and surface scale problems were related to the low carbon content of the alloy $(<60 \mathrm{ppm})$. As a result, experimental studies were performed using single crystal alloys containing up to $600 \mathrm{ppm}$. carbon. Generally, these higher carbon alloys resulted in improvements in the three problem areas previously discussed. For example, in the low carbon PWA1480 alloy, scale often covered onequarter to one-half of the airfoil. Alloys with greater than $150 \mathrm{ppm}$. carbon produced blades that exhibited virtually no scale.

In the early 1980's, Howmet Dover Alloy acquired an Electron Beam (EB) button melting furnace, shown in Figure 5, which was used in alloy cleanliness studies. A

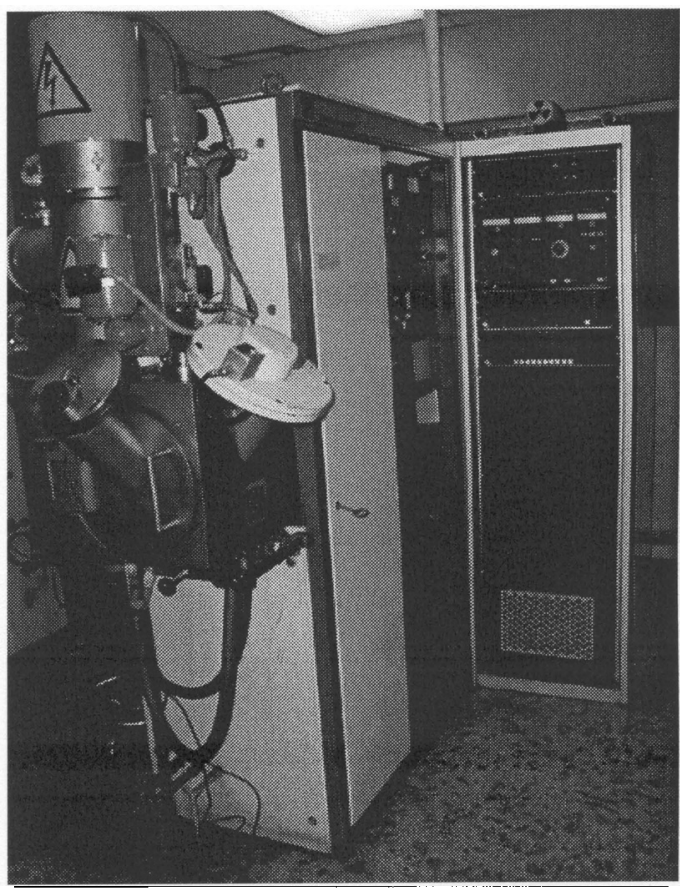

Figure 5: Howmet Dover Alloy EB button melting furnace

test button was produced in this furnace by drip melting a 650-gram alloy sample suspended above a water-cooled copper hearth into the hearth, as shown in Figure 6. This is performed under a vacuum of approximately 0.1 micron at a power level of 11.5 kilowatts. The melting program was controlled for roughly 8 minutes, which produced a 450 gram sample in the shape of a large hemispherical sample.

Analysis of the button was performed by taking an optical photograph and measuring the area of non-metallic oxides, that float to the surface of the button. The oxides float since they are less dense than the alloy. The result is expressed as the inclusion (raft) area normalized to a 
constant weight, or normalized oxide raft area (NORA). A typical EB button is shown in Figure 7.

This technique was used to evaluate alloy cleanliness with increased carbon levels in PWA1480 and PWA1484. The button results were consistent with the observations noted in the production of castings with respect to the beneficial

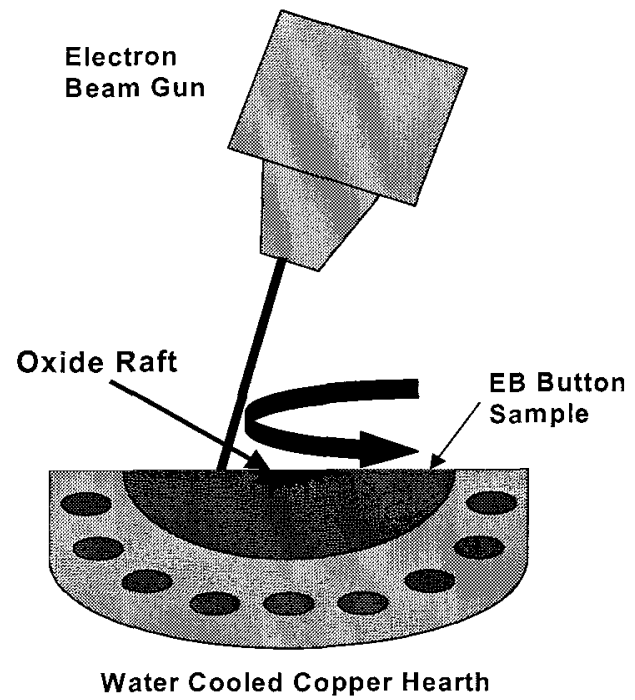

Figure 6: Electron beam button melting

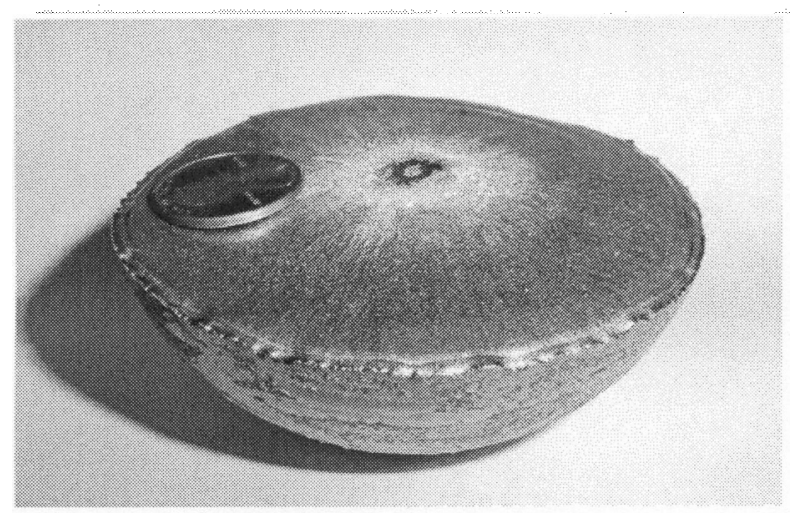

Figure 7: Typical electron beam button with oxide raft in center

effects of increased levels of carbon in these alloys. The data showed that the carbon effect becomes pronounced at $200 \mathrm{ppm}$. up to $600 \mathrm{ppm}$. At the $200 \mathrm{ppm}$. level, the cleanliness was superior to the alloy that was EB melted PWA1480, at $35 \mathrm{ppm}$. carbon. It was also noted that PWA1480 and PWA1484 were similar in behavior; however, the data also showed that PWA1480 required more carbon than PWA1484 to achieve the same high cleanliness, which may be related to the higher level of Ta in PWA1480.

\section{More Recent Studies of the Effect of Carbon Additions $\underline{\mathrm{CMSX}-4^{\mathbb{Q}}}$}

CMSX $-4^{\mathbb{E} 2}$ is a single crystal alloy patented and produced by Cannon-Muskegon Corporation. Industrial Gas Turbine (IGT) components produced from $\mathrm{CMSX}-4^{(B)}$ have experienced the cleanliness issues (inclusions) and scale formation similar to these issue observed with PWA 1480. The alloy is currently produced with a maximum of $50 \mathrm{ppm}$ carbon.

An investigation was undertaken using the EB button technique to evaluate the alloy at various carbon levels, in the manner discussed previously. Heats of $\mathrm{CMSX}-4^{\circledR}$ with carbon levels up to $1000 \mathrm{ppm}$ were produced and button samples were obtained from them. The results are presented, in graphical form in Figure 8.

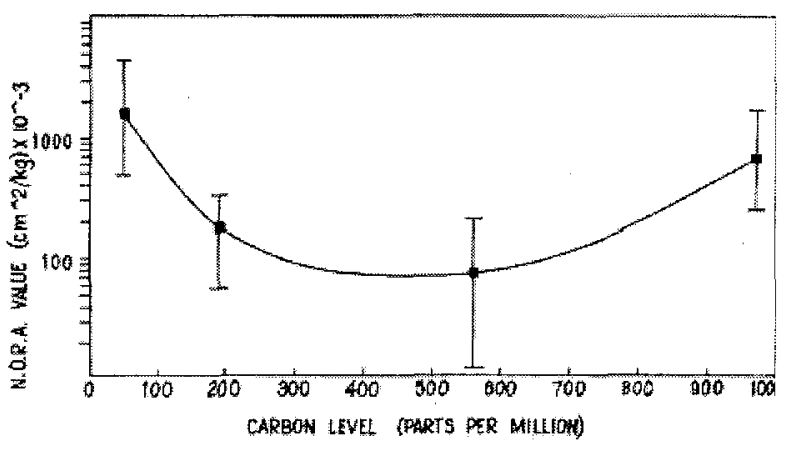

Figure 8: Carbon levels vs. NORA values for CMSX-4 ${ }^{\circledR 3}$

The results are similar, but not identical, to those obtained with other alloys. A parabolic relationship, exhibiting a defined minimum NORA value with a relatively flat range of several hundred ppm carbon on either side of the minimum. From a practical standpoint, this provides for a flexible working range of carbon where compromises may have to be made in determining the ideal carbon content for other reasons. At low carbon levels $(<100 \mathrm{ppm})$ there is insufficient carbon to reduce the oxygen adequately, resulting in higher levels of inclusions and a higher NORA value. As the carbon level is increased, the oxygen content of the alloy is reduced and cleanliness is improved. When the amount of carbon is increased above $600-700 \mathrm{ppm}$, the NORA values begin to increase. This is sometimes referred to as a polluting reaction whereby carbon breaks down the oxide lining of the furnace refractories in which the metal is being melted. 
Studies of the effect of increased carbon levels of CMSX$4{ }^{B}$ were performed on castings to determine the effect on quality. As in previous studies, additions of carbon were made to $\mathrm{CMSX}-4^{\mathbb{B}}$ to produce an alloy designated as CSCAD. The reduction in scale formation is dramatic with increased carbon levels. This is shown in the photographs of Figure 9 of conventional CMSX $-4^{\text {(B) }}(<50$ ppm carbon) to

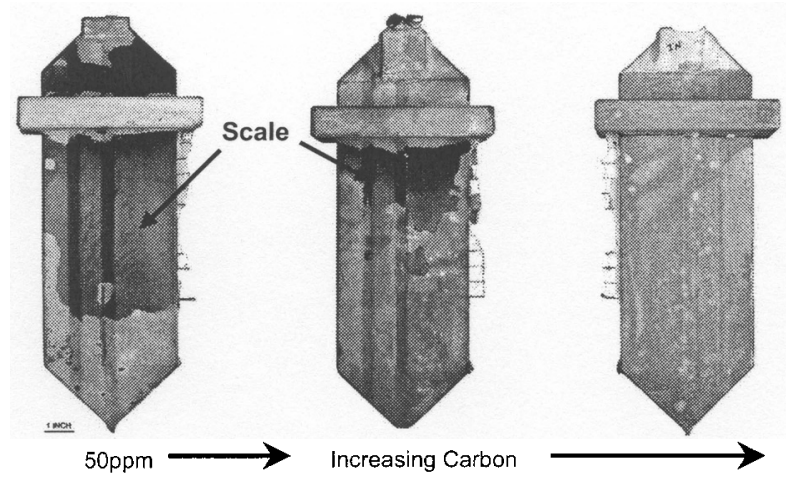

Figure 9: Surface scale on CMSX-4 ${ }^{\circledR}$ castings showing decreasing scale with increasing carbon content.

CSCAD ( $>100$ ppm carbon). With CSCAD the scale is virtually eliminated, even in castings that typically exhibit a significant amount of scale. With standard CMSX $-4^{\circledR}$ even the highest quality (lowest scale) castings exhibit a considerable amount of scale.

It has been reported by others that scale is not a significant problem for aerospace castings produced in CMSX $-4^{\circledR}$ (low carbon). This is attributed to the smaller size of these castings compared with IGT castings. In Howmet's experience, it is true that scale formation is exacerbated in larger castings.

\section{Determining Optimum Carbon Levels for Maximum Cleanliness in Single Crystal Alloys}

The single crystal alloys of this study produced results from the EB cleanliness tests similar to that depicted in Figure 6. The optimum carbon content differed among alloys. It was suspected that this was related to the amount of carbide formers in these alloys. A study of the available data showed that a linear relationship existed when the sum of the strong carbide formers $\mathrm{Ta}, \mathrm{Ti}$ and $\mathrm{W}$ were plotted against the optimum carbon content as determined from the Electron Beam cleanliness test. The relationship is most evident when atomic percentage is used, as shown in Figure 10. This relationship can also be expressed mathematically by the following:

$A t . \% C=(A t . \%(T a+T i+W)-3.8) / 10.5$
Thus it becomes possible to obtain the carbon level for optimum cleanliness from the alloy chemistry by using this relationship. As discussed earlier, there is broad working range about this optimum, generally, which allows for flexibility in choosing carbon levels in practice. The addition of carbon to CMSX $-4^{(3)}$ is covered by a Howmet patent $^{3,4}$.

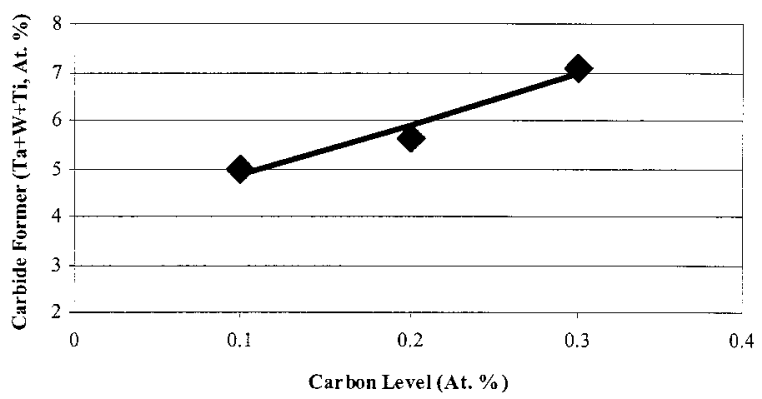

Figure 10: Relationship between ideal carbon and carbide former content.

\section{Conclusions}

1. Addition of carbon to the singles crystal alloys PWA 1480 , PWA 1484 and CMSX $-4^{\circledR}$ produces a dramatic reduction in oxide inclusions, sliver grains and scale formation, resulting in higher quality castings at lower cost.

2. Electron Beam cleanliness testing correlates well with cleanliness inspection results obtained on production castings.

3. Electron Beam cleanliness testing has shown that the optimum carbon level for cleanliness is a function of alloy chemistry, specifically, tungsten, tantalum, and titanium, which are carbide forming elements.

4. A mathematical relationship has been derived to enable one to determine the carbon level for optimum cleanliness from the chemistry of a single crystal alloy. 


\section{$\underline{\text { References }}$}

1. G.K.Bouse and J.R.Mihalisin, Superalloys,

Supercomposites, and Superceramics, Academic

Press, 1989, p. 108.

2. K. Harris, G. Erickson, U.S. Patent $4,643,782$

3. J. R. Mihalisin, J. Corrigan, R. Baker, E. Leonard, J. Vandersluis, U.S. Patent 5,549,765

4. J. R. Mihalisin, J. Corrigan, R. Baker, E. Leonard, J. Vandersluis, U.S. Patent 5,759,303

5. M.Clemens, Howmet Internal Reports and Personal Communication

6. G.R.Cole, Personal Communication 